\title{
On Platform Construction of English Vocabulary Learning in Higher Vocational Colleges Based on Mobile Micro Learning
}

\author{
Dan Peng \\ Wuhan Polytechnic, Wuhan, 430074, China \\ E-mail: 66581751@qq.com
}

Key words: Mobile micro learning; Vocabulary learning; Learning platform; Platform construction

\begin{abstract}
As a public basic course, College English in higher vocational colleges nowadays is faced with many problems like students' low quality and lack of interest in English. Vocabulary learning, as a crucial part in College English, is especially obsessed by such problems. Considering the limited time in class, the low efficiency of learning and the increasingly popularization of portable electronic devices and smart phone, it is urgent to carry out a new pattern of vocabulary learning based on mobile micro learning to solve these problems. Thus, this study attempts to combine vocabulary learning in higher vocational colleges and mobile micro learning, design and carry out several mobile learning platforms, and find out the best ways to apply these mobile platforms to class teaching and to improve students' interest in English learning and raise their scores. The author hopes that this study will realize the wider promotion and application of this pattern.
\end{abstract}

\section{Introduction}

Nowadays, the rapid development of Internet, the wide promotion of intelligent terminal and the increasingly rich learning resources greatly promote the development of mobile micro learning, as a newly emerging learning pattern. Recently, the Internet Plus Initiative boosts the development of Internet education, which starts a trend of the combination of technology and education. More and more teachers apply the mobile micro learning pattern into class teaching, especially in vocabulary teaching and learning. [1] However, confined by kinds of reasons, English teaching in higher vocational colleges nowadays has difficulty in improving class teaching, reforming class teaching and promoting experimental results. According to some research data, in more than two thirds of the class time, teachers focus on the transfer of the knowledge in textbooks and then check students' recitation by exercise and quiz.

Thus, the reformation of English teaching in vocational colleges is imperative. It is the same with the application of mobile terminal and the improvement of students' ability of mobile learning. And the reformation of traditional English vocabulary learning should follow this trend. Based on the similarities among network platform, social platform, audiovisual technology, vocabulary learning in mobile library and mobile micro learning in this study, they can all adopt this learning pattern.

Hence, this study attempts to find out how to make students read the required texts in fixed time and how to keep their long-term vocabulary mobile learning. [2]The author hopes that the research on the study situation of students adopting mobile micro learning pattern is theoretically and practically important to improve their learning outcome and meet their learning needs.

\section{Mobile micro learning}

\section{Definition of mobile micro learning}

Mobile micro learning, a newly emerging learning pattern, combines mobile learning and micro learning and embraces advantages of both patterns. It means that learners can take fragmented learning in their fragment time by virtue of mobile terminal. [3] In other words, through mobile 
terminal, learners can take micro learning at anytime and anywhere. Compared to micro learning, mobile micro learning is better in improvisation and interactivity. Improvisation means that learners can start learning at anytime and anywhere. And interactivity means that learners and teachers can communicate with each other freely on the internet.

\section{Characteristics of mobile micro learning}

a. Fragmentation of learning content

Through fragmented learning, learners will learn to divide the complex and difficult knowledge into fragments and then digest them one by one. It will strengthen their learning of required knowledge points, improve their ability of dealing with problems one by one, and help them complete their difficult learning tasks unconsciously.

b. Learning at anytime and anywhere

Mobile micro learning is not bound by time and place. That means, learners can make full use of their fragmented time and start learning at anytime and anywhere. It will help learners arrange their study time more flexibly and reasonably and improve their learning efficiency greatly.

c. Interactivity and personalization

If having access to Wi-Fi, learners and experts can communicate with each other by text message, voice chat and video chat through the mobile terminal. It is a good way to construct a knowledge network. And through the interactions, mobile micro learning can meet each learner's needs and solve individual problems so as to provide learners with pleasant learning experience.

d. Contextual learning activities

Supported by wireless network, mobile micro learning can create specific and vivid teaching situations. That means, it can put knowledge into corresponding situation which will enhance learners' understanding of knowledge and realize their long-term memory of specific knowledge. Educators can stimulate suitable learning context for learners to feel like they are really there and accordingly to enhance their understanding of knowledge.

e. Rich and shared learning resources

Because of the huge group of users and the interactivity of Internet, information and resources can separate and be shared quickly and conveniently. Each user can be the provider and the receiver of learning resources. Relying on the Internet, mobile micro learning can provide learners with countless learning resources and a platform to share their resources.

\section{Characteristics of English vocabulary learning}

\section{Enormous number and difficult to recite}

The enormous amount of English vocabulary greatly increases the difficulty of recitation. It is well known that the number of English vocabulary by now is more than one million and keeps a fast speed of increasing. Each word has specific pronunciation, form, meaning and fixed collocation. And the situations, that a word with different pronunciation or meanings, different words with the same pronunciation or different words with the same meaning, are very common. Besides, in different contexts, a word may have different meanings and usages. [4] These all increase the difficulty of learning. The enormous number and the indiscernible relations among English vocabulary make it difficult for learners to memorize and greatly reduce their reciting efficiency.

\section{Reciting at fragmented time}

The recitation of English vocabulary is fragmented. College students usually recite the English vocabulary taught in class. Some teachers may ask them or they ask themselves to recite words by dividing them into groups. And then, students will recite words at fragmented time like waiting in line, doing physical exercise and break time.

\section{Reciting in many ways}

The specific features and rules of pronunciation, form, meaning and others lead to the propose of many good reciting ways including associative memory, word-building, phonics, part-of-speech 
tagging and so on. [5] When reciting words, learners should choose suitable ways which will improve their learning efficiency and stimulate their learning interest.

\section{Reciting persistently}

To overcome the difficulties of enormous number and short-term recitation, learners should keep persistent recitation. The recitation of English vocabulary is a long-term task. Therefore, on one hand, learners should make sure the quantity accumulation. That means, they should grasp as many words as possible. [6] On the other hand, learners should assure their learning quality. That means, they should review and strengthen what they have recited in time. However, to follow these two aspects above is fairly hard. Thus, to keep persistent learning, interest is particularly important.

\section{To design and carry out the platforms of mobile micro learning}

Based on a questionnaire survey of students at Wuhan Institute of Technology, we find that all of them have mobile phone and almost $90 \%$ of them have smart phone. Almost everyone have signed up for QQ, Tencent Weibo and 90\% of them have signed up for Wechat. And their phones are mainly based on Android OS, Symbian OS and Iphone OS. Through investigation of mobile learning software in this three operating systems and teachers' trial experience, we recommend the following learning software to students.

This software mainly contains 9 parts: word learning, song appreciation, word quiz, personal center, interactive community, English information, daily sentence, learning experience and word query. The main contents of each part are as follows.

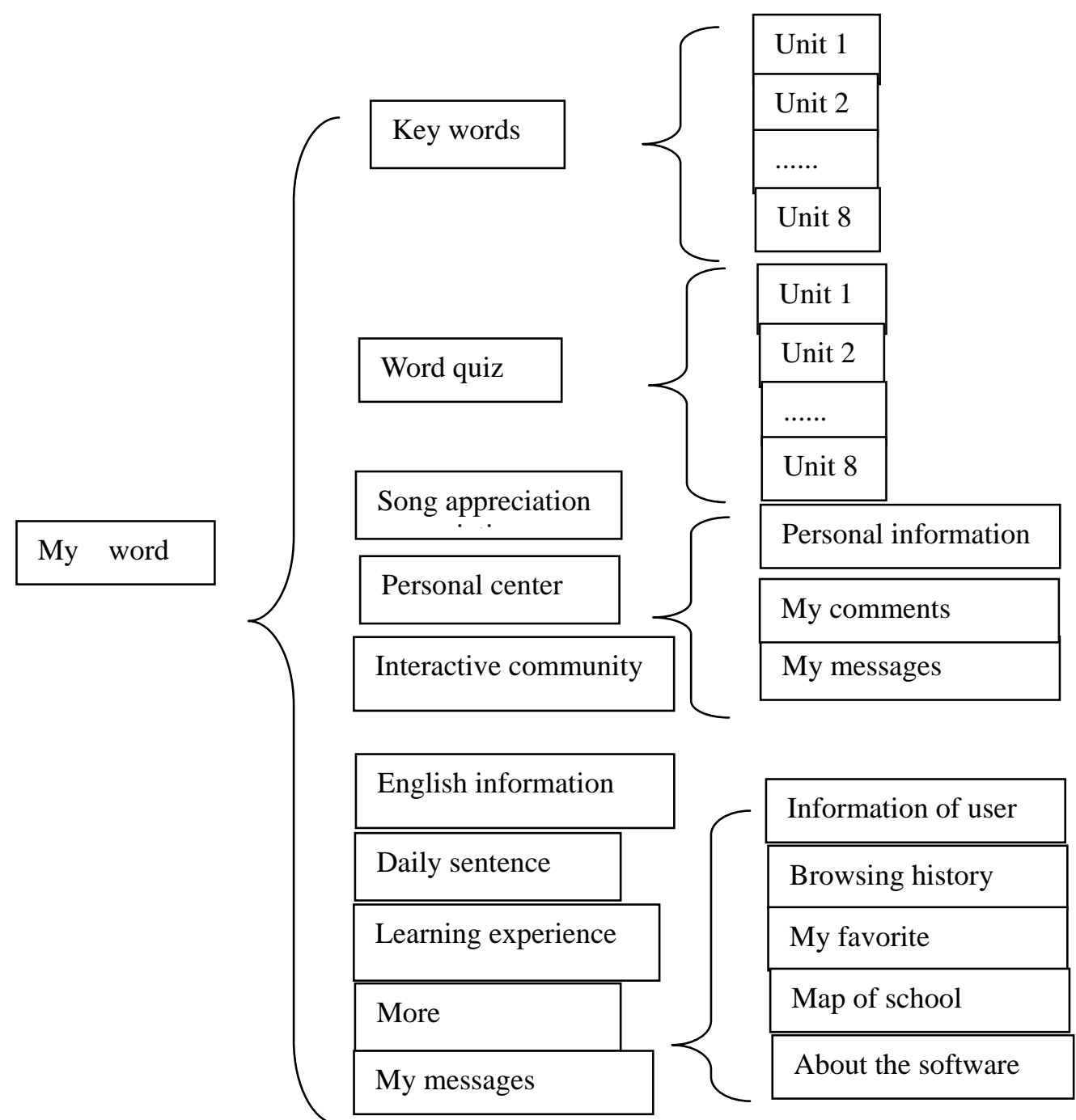

Figure 1: Construction of Flipped Classroom Teaching Model of English Vocabulary Learning 
The word learning part is in line with the units of the textbook Integrated Course on Practical English in Higher Vocational Colleges. Since most students show great interest in English songs, the Song Appreciation part will not only make them relax, but also extent their English vocabulary. The Word Quiz part mainly checks what they have learned by test and quiz. The Personal Information part mainly contains the brief information of registers that can make comments, favor and share certain information and can also revise their information. The Interactive Community part functions as a platform for learners' communication and suggestions of improvement. The administrator will collect their suggestions and reply them by e-mail. The English Information part provides English information by virtue of the function of RSS -- recourse collection. The Daily Sentence part mainly provides inspiring sentences for learners. Through these sentences, learners can get their pronunciation, translation; meaning and beautiful pictures which help learners feel the charming of English culture and strengthen their confidence in English learning. The Learning Experience part provides a platform for learners to share their learning experience and notes with others only when the administrators approve it. The Word Query part combines the powerful query capability of PowerWord so that learners can search words as much as possible. Besides, the client will also provide the history of searching, favoring and receiving information and remind users to update the system.

\section{Conclusion}

Faced with many problems like students' low quality and lack of interest in English, college English in higher vocational colleges should learn from the new learning patterns like ubiquitous learning and mobile learning based on the Big Data, Cloud Computing, Internet and mobile network. Teachers there should reform their teaching methods and innovate their teaching pattern. Thus, taking full advantage of multimodal teaching and mobile teaching and making full use of students' mobile terminal, this study attempts to put forward with a new pattern called mobile micro learning by applying mobile terminal into class teaching and learning.

\section{Acknowledgement}

In this paper, the research was sponsored by Foundation of Hubei Educational Committee (Project No. 2016GB036) and Foundation of Hubei Educational Committee (Project No. 2016322).

\section{References}

[1] Using Mobile Phones for Vocabulary Activities: Examining the Effect of Platform. Glenn Stockwell. Language Learning. 2010

[2] The lexical plight in second language reading: words you don't know, words you think you know, and words you can’t guess. Laufer, B. Second language vocabulary acquisition: A rationale for pedagogy. 1997

[3] Using mobile phones in English education in Japan [J]. Patricia Thornton, ChrisHouser. Journal of Computer Assisted Learning. 2005 (3)

[4]. Microlearn-ing:Emerging Concepts,Practices and Technologies aftere-Learning. Theo Hug,Martin Lindner,Peter A Bruck. Proceedings of Microlearning 2005.

[5] Prospect for Cell Phones as Instructional Tools in the EFL Classroom: A Case Study of Jahangirnagar University, Bangladesh [J] . Roksana Begum. English Language Teaching. 2011 (1)

[6] Assisting the uptake of on-line resources: why good learning resources are not enough [J]. Gayle Calverley, Kerry Shephard. Computers \& Education. 2003 (3) 